\title{
Cancer: the rise of the genetic paradigm
}

\author{
J. Michael Bishop \\ Department of Microbiology and Immunology and the G.W. Hooper Research Foundation, University of California, \\ San Francisco, San Francisco, CA 94143
}

\section{Introduction}

Peyton Rous opened his Nobel lecture of 1966 with the following passage: "Tumors destroy man in a unique and appalling way, as flesh of his own flesh which has somehow been rendered proliferative, rampant, predatory and ungovernable. [Tumors] are the most concrete and formidable of human maladies, yet despite more than 70 years of experimental study they remain the least understood. ... What can be the why for these happenings?"

We now believe that we know the "why for these happenings," and it takes a remarkable form. Two sorts of genes govern the proliferation of our cells: proto-oncogenes, which serve as accelerators to activate the genes of the cell; and tumor suppressor genes, which serve as brakes to retard the growth of cells. Jam an accelerator or remove a brake, and the cell may be unleashed to relentless proliferation.

Starting with this simple image, we are now on the verge of a detailed portrait of cancer cells, of how they arise, of how they prosper, of what new might be done against them. My purpose here is to trace the historical roots of his image, to show how the intellectual edifice that now houses cancer research was constructed. My strategy will be to explore five major themes that have converged to give us that edifice. It is a story rich with humanity and with lessons on how science proceeds.

\section{The neoplastic phenotype is heritable}

The first and primeval theme is that the phenotype of neoplastic cells is heritable, no matter what its cause. One cancer cell begets two others and so on ad infinitum, almost without exception. Thanks to Rudolph Virchow, the heritable nature of the neoplastic phenotype was perceived at the dawn of the cell theory itself. It was Virchow who, in 1858, coined the Latin aphorism by which the cell theory became known: onmis cellulae cellula: "all cells come from cells." To support this view, Virchow pointed out that the cellular components of metastatic cancer generally resemble those of the primary tumor, as if they all might be relatives.

Then Virchow reached even further, by reasoning that if all the cells of a tumor are relatives, then they may have a common origin from a single cell. Thus did Vir- chow dimly perceive what we now hold as fundamental tenet: most if not all tumors are monoclonal, with single progenitors, rather than polyclonal, with multiple origins.

The clonality of tumors has become an article of faith among most students of cancer. But there is an irony here, because the heritable nature of the neoplastic phenotype bespeaks a genetic stability that is illusory. In reality, we now know that an expanding clone of potential cancer cells diversifies with startling rapidity, a rapidity that is essential to the success of tumorigenesis. Every tumor represents the outcome of an individual experiment in cellular evolution, fueled by a genetic instability that we have brought to view only recently, and overseen by relentless selection for advantageous cellular properties.

If cancer begins as a single cell that eventually progresses to a full blown malignancy, what initiates the deadly sequence? For at least two centuries, the focus has been on external causes. Only in the past two decades, however, have we convinced ourselves that those causes might be united by a common mechanism: the mutation of DNA, the second of our converging themes.

\section{External carcinogens}

In 1761, Dr. John Hill of London published a claim that the inhalation of snuff caused nasal cancer. This is reputed to be the first formal report of external carcinogenesis. Fourteen years later, Percival Pott achieved lasting fame when he reported that the chimney sweeps of Britain were highly prone to cancer of the scrotum and attributed this to the soot of incompletely burned coal. The Danes had a similar problem with chimney sweeps, which they proceeded to ameliorate by the use of protective clothing, in what is thought to be the first successful program of cancer prevention.

These crude efforts at epidemiology were far ahead of their time, and recognition of their significance languished until late in the 19th century. Then industrial exposures to large quantities of noxious agents returned the issue of external carcinogens to center stage. In quick succession, paraffin oils, mining dust, arsenic, and aniline dyes came under suspicion. And the importance of physical agents also became apparent, in the form of 
skin cancers attributed to either excessive exposure to sunlight or exposures to the newly discovered X-rays.

Could these experiments of nature be reproduced in the laboratory? The question was answered first by Clunet, who in 1908 reported that deliberate exposure to $\mathrm{X}$-rays could induce skin cancer in rats. Experimental carcinogenesis with chemicals applied to the skin proved more difficult, in part because early trials were performed with rats and dogs, species we now know to be exceptionally resistant. In 1915, however, Yamagiwa and Ishikawa reported the induction of cancer in the skin of rabbit ears by the application of coal tar. They had fortuitously chosen a sensitive species and anatomical site. And they had been persistent: success came after application of the carcinogen every two or three days for a period of more than 100 days.

Soon thereafter, Tsutsui, a student of Yamagiwa, demonstrated chemical carcinogenesis on the skin of mice, a more tractable system than rabbit ears. The exploration of chemical carcinogenesis was now properly launched. Elated with all this, Yamagiwa wrote a Heiku, in his own masterful calligraphy. Loosely translated, it read: "Cancer was produced. Proudly I walk a few steps."

Yamagiwa's elation was justified. His findings are regarded as a landmark in the history of cancer research, because they pointed the way to the identification and characterization of chemical carcinogens, and because they exemplified the protracted nature of tumorigenicity. But sometimes there is no justice in contemporary judgment. In 1913, the Danish scientist Johannes Andreas Grib Fibiger announced the induction of stomach cancer in rats by invasive nematode worms. The work is now little noted, but it was Fibiger who received the Nobel Prize for experimental carcinogenesis in 1927, not Clunet or Yamagiwa.

The pioneering work of Yamagiwa was performed with crude coal tar and mixtures of organic chemicals. But in 1930, Ernest Kennaway in London demonstrated carcinogenicity with a synthetic and purified dibenzanthracene, providing the first rigorous identification of a single chemical carcinogen. Soon thereafter, carcinogenesis affecting internal organs was achieved, by feeding chemicals to rats. The generality of external carcinogenesis was now well established.

\section{Carcinogens as mutagens}

The discovery of explicit carcinogens immediately raised the issue of how they might be acting. Again, pride of place belongs to X-rays, whose mutagenicity was demonstrated by H.J. Muller in 1928, using Drosophila melanogaster. At the time, Muller had no apparent scientific interest in cancer. Yet his discovery underlies virtually all contemporary thinking about the mechanisms of tumorigenesis.

Within a decade of Muller's discovery, the chemical carcinogen 3-methylcholanthrene had also been shown to be mutagenic (this time, in mice). By 1948, Demerec was asserting that just as all carcinogens are probably mutagens, all mutagens would likely prove to be carci- nogenic. Then the going got tough. How could the mutagenicity of carcinogens be explained? The answer was obscured by two difficulties. First, some of the carcinogens were curiously unreactive in chemical terms. Why then did they have biological effects? And second, what was the molecular target of the carcinogens? Would it be the same as the target for mutagens?

The first of these puzzles, the chemical puzzle, was solved with the discovery that the body often betrays itself. In the process of detoxifying chemicals, it can create highly reactive intermediates that represent the actual carcinogens. The possibility of this metabolic activation was first suggested by Boyland in 1935, then put on a firm experimental ground three decades later, particularly by Elizabeth and James Miller in Madison, Wisconsin.

Identification of the reactive forms of chemical carcinogens helped clarify the search for their molecular targets, but progress was still slow. You would think that the work of Avery and his colleagues on DNA, followed by the lightning strike of Watson and Crick in 1953, might have brought DNA quickly to the fore in the study of carcinogenesis. But strange to say, it did not. The idea, the dogma, that proteins were the crucial targets for carcinogens proved to have great staying power. As late as 1970, James Miller was still arguing that "in no case do we know unequivocally the nature of the molecular target(s) critical to the induction of [the] carcinogenic process." Even knowing that certain carcinogenic esters reacted with DNA and were mutagenic, Miller felt obliged to caution that "the mutagenic activities of these esters are a consequence of their electrophilic reactivities and are not necessarily related to their carcinogenic activities."

In any poll of modern molecular biologists, you could probably get a rousing majority for the view that carcinogens act by affecting DNA. But still, there are lingering difficulties. It all began promisingly enough, with the development by Ames and others of tests that allowed the detection of mutagenicity in cultures of bacteria or vertebrate cells. At first, there appeared to be a direct correlation between relative mutagenicity in these short term tests and relative carcinogenicity in rodent models. But now we know that perhaps half of all the substances that are carcinogenic in rodent tests do not score as mutagens in the short term tests, a discrepancy that remains inadequately explained. One standing rationalization is that nonmutagenic carcinogens are cytotoxic, and this leads to compensatory cellular proliferation that favors intrinsic mutagenesis.

These bothersome ambiguities have caused no end of strife in the efforts to identify and regulate the use of carcinogenic agents. And they illustrate why efforts to study the mechanisms of external carcinogenesis have contributed only tangentially to the search for the inner malady of cancer cells.

\section{Cytogenetics and cancer}

As scientists struggled with the identity and mecha- 
nisms of external carcinogens, another line of enquiry emerged to provide more substantive clues that the genetic apparatus is at fault in tumorigenesis. This was cytogenetics and the demonstration that cancer cells frequently harbor abnormal chromosomes-the third of our converging themes.

In 1903, Walter Sutton published a paper entitled "The chromosomes in heredity." By studying the germinal cells and zygotes of grasshoppers, Sutton had reached a series of pathbreaking conclusions: first, that each somatic cell contains two sets of chromosomes; second, that the pairs of chromosomes are each physically distinctive; third, that in mitosis, each daughter cell gets a complete set of chromosomes, but the individual members of chromosome pairs segregate at random; fourth, that each gamete receives only one set of chromosomes, as a consequences of reduction division (meiosis); and fifth, that all of these facts combine to suggest chromosomes as the likely carriers of inherited traits. In one fell swoop, Sutton had created the science of cytogenetics, just three years after the rediscovery of Mendelian genetics.

At the time of his momentous publication, Sutton was a 25-year old student with E.B. Wilson at Columbia University. Sutton never published another paper. Instead, he went on to become not a scientist, but a surgeon, and to die prematurely at the age of 39 . He left behind insights that can easily stand in the history of genetics with those of Mendel, and Watson and Crick.

We can credit Sutton with the creation of cytogenetics, but it was Theodor Boveri who took the pursuit into the realms of cancer. In the same year as Sutton's publication, Boveri produced an intuition that still reverberates through the world of cancer research. Based on his studies of mitosis in Ascaris worms and sea urchins, Boveri hypothesized that cancer might be due to abnormalities of chromosomes, particularly the gain or loss of chromosomes from asymmetrical segregation. The hypothesis proved to be remarkably prescient in its assumption that specific chromosomal elements govern cell division; in its recognition that either gain or loss of genetic function might cause trouble; in its anticipation of genetic dominance and recessiveness; and coming, as it did, nearly a century before genetic excesses and deficiencies would be soundly implicated in tumorigenesis.

The prescience of Boveri has reached magnificent fruition in our time. In 1960, Nowell and Hungerford teamed up to identify the Philadelphia chromosome, an abnormality found consistently in cells of chronic myelogenous leukemia and the first chromosomal anomaly specifically associated with any neoplasm. The resolution available to Hungerford and Nowell failed to reveal the full nature of the Philadelphia chromosome, which Janet Rowley later showed to be the result of a reciprocal translocation between chromosomes 9 and 22. Those of you who persist in thinking of cytogenetics as simply peering through a microscope should read the crucial paper from Rowley: it is a gem of ingenuity.

By the end of 1989, editors at the late, lamented journal Cancer Cells were able to compile a list of 114 chro- mosomal aberrations associated in a specific manner with cancer. And a recent review in Nature listed 52 chromosomal translocations whose breakpoints have received molecular attention sufficient to identify the affected gene or genes. Thus, cytogenetics has succeeded in pointing to the genetic apparatus as the ailing organ of the cancer cell. But the implication that malfunctioning genes might propel neoplastic growth could not be tested with microscopy. Instead, it was the study of tumor viruses that produced the first explicit example of cancer genes-the fourth of our converging themes.

\section{The discovery of tumor viruses}

At the turn of this century, the microbial theory of disease was in full cry. It seemed as if all disease might have external, perhaps microbial causes. So it was only natural that the discovery of viruses would lead immediately to enquiries about whether these agents might cause cancer. The first success came in 1908, when the Danish scientists Vilhem Ellerman and Oluf Bang reported that they could transmit leukemia from one chicken to another with an infectious extract of blood cells. The work was dismissed by most authorities because leukemias were not in those days considered to be malignancies, and because chickens were not thought to be interesting.

Peyton Rous thought otherwise. So in 1909, he undertook a series of experiments that led to the discovery or a virus that causes sarcomas in chickens, which we now know as Rous sarcoma virus. From his discovery, Rous constructed the argument that perhaps viruses cause cancer in humans as well. The scientific community of the time was not thrilled. They viewed the findings in chickens as peripheral, the proposal for human cancer viruses as nonsense.

It is often said that Rous eventually gave up the study of his chicken virus because of ridicule. But by his own report, he abandoned the work because he could not detect viruses in cancers of rodents. He felt that if the phenomenon he had discovered was not universal, it was not worthy of pursuit. He may have been right in principle, but he was wrong in reality.

The viruses that Peyton Rous renounced would not go away. Over the decades that followed his great discovery, a series of hard fought intellectual battles slowly but firmly established the point that a great diversity of viruses are capable of causing cancer in either experimental or natural circumstances, and in virtually every species of vertebrate tested.

Much of the difficulty in winning those battles arose from a persisting bias against viruses as causes of cancer. For example, in the 1940's, John Bittner deliberately disguised his discovery of Mouse Mammary Tumor Virus by calling it "milk factor." Asked to explain this decades later, he remarked: "If I had called it a virus, my grant application would have automatically been put in the category of 'unrespectable proposals.' As long as I used the word factor, it was respectable genetics." In addition, Bittner was loathe to offend his supervisor, C.C. Little, who was passionately committed to a genetic explana- 
tion for the vertical transmission of mammary carcinomas in mice.

\section{Viral oncogenes}

As the reality of tumor viruses became secure, two schools of thought sprang up. One school argued that we should search for viruses in human cancer, that viruses must be a common cause of this disease. The other school held that since there may be many causes of cancer, we would be better off to use viruses in search of the central molecular mechanisms by which the disease arises.

Against all reasonable odds, both views have been vindicated. On the one hand, viruses have been implicated in a number of human cancers; carcinoma of the liver and of the uterine cervix are the most prevalent examples, at present. On the other hand, the genetic simplifications offered by viruses have led us to the heart of the cancer cell, helping us to ferret out the molecular anomalies that sire the cancer cell.

How might viruses cause cancer? For years, there was no sensible hypothesis to answer that question. But eventually, genetics came to the rescue. An early notable step was taken by Mike Fried in 1965, when he described a conditional mutant of polyoma virus in which cellular transformation was temperature-sensitive. Unfortunately, viral replication was also affected, so it was impossible to discern whether transformation was a primary or secondary consequence of viral gene expression.

The issue came clear in 1970, an annus mirabilis in the history of tumor virology. It was, of course, the year of reverse transcriptase. But it was also the year that src was brought to view. First, Steven Martin used Rous sarcoma virus to isolate mutants that were temperaturesensitive solely for transformation. By this means, he was able to show that a viral gene was required for both the initiation and maintenance of transformation, yet made no contribution to viral replication. The gene was soon dubbed v-src and the generic term "oncogene" also came into general use. Second, Peter Duesberg and Peter Vogt reported the first of their studies showing that the transforming ability of Rous sarcoma virus could be lost by deletion, and that the deletions provided a physical definition of the oncogene $\mathrm{v}$-src.

Then, in a spirited race that ended in a dead heat, Duesberg and his colleagues on the one hand, Weissman and his on the other, mapped v-src to its location on the genome of Rous sarcoma virus. But do not let the term "map" mislead the young among you with a false image of restriction enzymes and Southern blots: this was life before recombinant DNA: the experiments were models of imagination and technical tours de force.

The discovery that the virus of Peyton Rous uses a gene to elicit cancer brought clarity to what had been a muddled business. There had been hints before that the elemental secrets of cancer might lay hidden in the genetic dowry of cells. But here in Rous sarcoma virus was an explicit example of a gene that can switch a cell from normal to cancerous growth.
Now a more ambitious question arose. Might the cell itself have such genes? Can the complexities of human cancer be reduced to the chemical vocabulary of DNA? With these questions, we arrive at a chapter of the story that is in part my own. Poets often fashion careers out of confession, but I find it an uncomfortable exercise for a scientist. Still, the chapter must be told, so I beg your indulgence and proceed.

\section{Proto-oncogenes}

The chapter began when Harold Varmus joined me in San Francisco, late in 1970. Harold and I began our work together studying the synthesis and integration of retroviral DNA. In due course, however, we were led to the question of "whence v-src?" The question was energized by two considerations.

First, there was an evolutionary puzzle. The genome of Rous sarcoma virus has three genes devoted to viral replication. But v-src is not one of these: it is fully dispensable, without harm to the virus. Why then is it there? Second, there was the Oncogene Hypothesis from Robert Huebner and George Todaro, which attributed all cancer to the activation of oncogenes, implanted into vertebrate germ lines by retroviral infection eons ago. We thought we might get some purchase on both of these issues by looking for a counterpart of v-src in normal cells.

It required the better part of four years, but in the end, we reached the conclusion that vertebrate cells do indeed carry a version of $s r c$. But the vertebrate $s r c$ proved to be a normal cellular gene, not a retroviral intruder. The results stood the Oncogene Hypothesis on its head.

Eventually, it became clear that $s r c$ is indeed a normal cellular gene (c-src), grafted into the virus of Peyton Rous by an accident of nature we call "transduction." So the virus is an inadvertent pirate; the booty is a cellular gene with the potential to become a cancer gene when mutated in certain ways.

Now an additional question presented itself. Could we generalize the principle of transduction? Had the oncogenes of other retroviruses also originated from cellular genes? To pursue the generality of transduction, we turned first to an avian virus known as MC29, which attracted our attention because it induces carcinomas, the most prevalent of human cancers. Lacking any sort of mutant that might define the oncogene, we and others made the assumption that the genomes of MC29 and its necessary "helper virus" were congenic except for the presence or absence of the oncogene. That assumption soon led to both the viral oncogene we now call $\mathrm{v}-m y c$ and its cellular counterpart, c-myc. The example of cellular $s r c$ was not an exotic anomaly: it was an archetype.

We were nevertheless rebuffed by two referees, who took stances diametrically opposed to one another. One argued that the story of myc was mundane, that the genesis of all oncogenes had become self-evident from the results with src alone. The other referee argued that we could not claim to have generalized the principle of 
transduction unless we could provide yet another example: $m y c$ alone would not suffice. Imagine how bored the first referee must have been, and how pleased the second, as other examples began to tumble out. Eventually, the tally of transduced oncogenes in retroviruses grew to more than two dozen, a formidable armamentarium for the experimental analysis of tumorigenesis.

As transduction by retroviruses came into common discourse, the need arose for a generic term to describe the cellular progenitors of retroviral oncogenes. The first to find general usage was "cellular oncogene." But some investigators were uncomfortable with this term, because of its unwarranted implication that the cellular genes might be tumorigenic in their native state.

Then Howard Temin provided a useful inspiration with his suggestion that all retroviruses arose by the cobbling together of disparate genetic elements in the cell, with intermediates that he called proto-viruses. So in playful homage to Howard, I began to use the term "proto-src." The generic "proto-oncogene" followed in short order. In the interim, proto-oncogene has come into general use, as the colloquial counterpoise to oncogene. It has also become an embarrassment, because the precise connotation of the word is that of prototype rather than progenitor, not far removed from the offensive connotation of the term "cellular oncogene."

\section{Implicating proto-oncogenes in tumorigenesis}

It had once seemed that the lessons to be learned from retroviral oncogenes might apply only to the tumors that viruses induce in animals, that the oncogenes of retroviruses might be alley cats of evolution with little importance to human kind. The discovery of proto-oncogenes inspired hope that this narrow view might be wrong. Perhaps proto-oncogenes exemplify a genetic keyboard on which all manner of carcinogens might play. Any influence that can damage a proto-oncogene might give rise to an oncogene, even if the damage occurred without the gene ever leaving the cell, without the gene ever encountering a virus. In this view, proto-oncogenes become precursors to cancer genes within our cells, and damage to genes becomes the underpinning of all cancers-even those that are not caused by viruses.

That scheme would not have set well with Peyton Rous. Consider this excerpt from his Nobel lecture: ". . . no inkling has been found ... of what happens in a cell when it becomes neoplastic, and how this state of affairs is passed on when it multiplies. ... A favorite explanation has been that oncogenes [carcinogens] cause alterations in the genes of cells of the body, somatic mutations as these are termed. But numerous facts, when taken together, decisively exclude this supposition."

As the passage indicates, Rous was no less fallible than other Nobel laureates. But he could be a bulldog in debate, witness this excerpt from a lead article he wrote for Nature in 1959: "A hypothesis is best known by its fruits. What have been those [fruits] of the somatic mutation hypothesis? It has resulted in no good thing as concerns the cancer problem, but in much that is bad.... Most serious of all the results of the somatic mutation hypothesis has been its effect on research workers. It acts as a tranquilizer on those who believe in it. .."

Rous had two reasons for his position against somatic mutations: first, he argued that many carcinogens were not demonstrably mutagens, citing tumor viruses as a prime example (which we now know to be erroneous); and second, he found the genetic view of cancer "fatalistic" and feared that it might discourage efforts to cure cancer through chemotherapy (here again Rous was wrong, although the cures he hoped for still largely elude us). The skepticism of Peyton Rous about the role of mutations in tumorigenesis has had its latter day advocates. But experiment has outflanked skepticism, by revealing proto-oncogenes as targets of tumorigenic damage in diverse settings.

The first hints came again from the study of retroviruses. Most retroviruses do not have oncogenes, yet many of these viruses cause tumors. In 1981, it became apparent that most do so by accidentally hectoring protooncogenes at their site of residence in chromosomes: insertion of retroviral DNA activates the affected gene in an unwanted manner, a "gain of function" mutation that is pathogenic. Through good fortune, the first example of such "insertional mutagenesis" involved c-myc, one of the few proto-oncogenes then defined and, thus, available for testing. There were many other examples that would have been blind alleys, had they come under study first.

One year later, the molecular conundrum of chromosomal translocations was solved through similar good fortune. The first examples to be examined were B-cell tumors of mice and men, and in both instances, the characteristic translocations activated the c-myc by one means or another. For good measure, c-myc was also the first proto-oncogene found in amplified DNA, the other major chromosomal anomaly that we now associate with diverse tumors. Myc has been a good provider for molecular oncologists.

A very different line of enquiry provided additional evidence to incriminate proto-oncogenes in tumorigenesis. In 1979, Shih and Weinberg, motivated by the precedents of tumor virology, used DNA-mediated gene transfer to demonstrate the presence of a biologically activate oncogene in chemically transformed cells. That finding led, in turn, to the discovery that many human tumors harbor mutant versions of ras proto-oncogenesonce again, culprits already familiar to us from the study of retroviruses.

As the exploration of genetic damage in tumor cells proceeded, the repertoire of proto-oncogenes grew. The sum now exceeds one hundred. And as the tally grew, so did the tie between proto-oncogenes and cancer. It now appears that most if not all forms of cancer may contain damage to one or another specific proto-oncogene. In each instance, the damage somehow unleashes the gene or its protein product, driving the cell to relentless proliferation. A genetic engine for the cancer cell has been found. 


\section{Tumor suppressor genes}

The discovery and elucidation of proto-oncogenes gave substance to the excess of chromosomal function predicted by Theodor Boveri. But what of the chromosomal deficiencies he also imagined? The first functional hint of these came when Henry Harris and his colleagues discovered that the fusion of normal and cancer cells often suppresses the neoplastic phenotype: the hybrid cells grow normally rather than as cancer cells.

Such were the early results, crisp and clear. Then a period of confusion set in. As the combination of cells fused with one another grew, so did the number of conflicting results-due, in part, it seems, to the use of crosses between cells of different species. By now, however, the dust has settled. There is general agreement that cancer cells appear to be defective in functions that are required for the regulation of cellular proliferation and other behavior. Fusion with a normal cell restores the necessary functions and, thus, suppresses cancerous growth.

The responsible genes became known as "tumor suppressor genes," and their defectiveness in cancer cells was taken as an example of recessive genetic damage. In some instances, it has been possible to assign the gene or genes responsible for phenotypic suppression to a particular chromosome, but none of these genes has yet been identified physically through the use of cell hybrids. Instead, the route to the isolation of tumor suppressor genes lay through the study of inherited cancer-the last of our convergent themes.

\section{Congenital cancer}

In 1866, the French neurosurgeon and anthropologist Paul Broca analyzed the pedigree of his wife's family and recognized a hereditary predisposition to breast cancer. In the decades that followed, descriptions of inherited cancers continued to appear sporadically. But at least two difficulties kept these descriptions from having a decisive impact. First, examples of familial cancer were rare and the nonfamilial tumors that dominated clinical experience might be due to something entirely else. Second, the patterns of inheritance were often confusing, with diverse confounding factors.

There was a special case, however, that from the beginning was not subject to these difficulties: inherited deficiencies in DNA repair. The first of these to be unveiled was Xeroderm Pigmentosa, a congenital syndrome featuring extreme sensitivity to sunlight and a frightening predisposition to skin cancer. The instant that James Cleaver recognized this syndrome to be a deficiency in the repair of damage inflicted on DNA by ultraviolet light, the mutational theory of cancer took on new luster. And a warning was sounded that we should expect other forms of hereditary cancer to arise from deficiencies of DNA repair, as we now know to be the case.

Familial cancers not obviously based on defective DNA repair were less transparent. The first of these to come under close scrutiny was retinoblastoma, a rela- tively rare tumor restricted to children under the age of five. The disease is encountered in both a sporadic and a familial form. The pattern of inheritance for familial tumors appeared to be autosomal dominance, but that proved to be a masquerade.

The unmasking began in 1969, when Robert DeMars proposed that "many of the pedigrees for [retinoblasto$\mathrm{ma}$ ] families are consistent with the notion that one of the parents in these families might be heterozygous for a recessive [mutation] and that the neoplasms appear as a result of subsequent somatic mutations in which individual cells become homozygous for a recessive neoplasm-causing gene." The quote comes from the published discussion of an M.D. Anderson Symposium and must rank among the most perceptive comments ever recorded in such an ephemeral venue. Two years later, Alfred Knudson published the first of his seminal papers that formulated how many genetic events might be involved in the genesis of retinoblastoma (he proposed twol, how those events might represent independent mutations, and how inheritance of one of these mutations would explain the increased susceptibility to retinoblastoma in affected families.

The theorists were soon helped by experiment. The first useful step was the detection of a chromosomal abnormality in some of the sporadic and inherited retinoblastomas: an interstitial deletion at $13 \mathrm{q} 14$, pointing to a possible recessive lesion of the sort first imagined by DeMars, and giving that lesion a potential chromosomal locus for the first time. Then Esterase-D was found to be a polymorphic marker linked to the inheritance of retinoblastoma and to the chromosomal locus of the deletion. Analysis of this marker provided the first physical evidence that the schemes proposed by DeMars and Knudson might be correct. A complete and homozygous null for the locus was even found in some tumors.

With the advent of restriction fragment linked polymorphisms, it became possible to authenticate the chromosomal lesions of hereditary retinoblastoma beyond all doubt, and to perceive some of the ways that alleles of the supposed tumor suppressor gene might be inactivated or lost. The story reached its first climax in 1986, with the isolation of the retinoblastoma gene, RB1. After decades as chimera, tumor suppressor genes had become a physical reality.

The uncovering of $\mathrm{RBl}$ and its role in tumorigenesis dramatized the way in which epidemiology, population genetics, cytogenetics, and molecular biology can be joined into an integrated assault on cancer. And it was a harbinger of much more to come. Evidence has now been obtained for recessive genetic lesions in most if not all forms of human cancer. At least a dozen of the affected genes have been identified directly by the use of recombinant DNA, and there are probably many more to come. It is worth noting that even the earliest fruits of the often-maligned human genome project are making these genes easier to find. And in continuation of the precedent established by retinoblastoma, most other familial cancers are apparently based on recessive, inherited deficiencies of tumor suppressor genes; the only possible 
exception for the moment is ret, ostensibly a proto-oncogene. Indeed, the familial syndromes have remained major points of departure in the isolation of additional tumor suppressor genes.

\section{Conclusion}

So we have arrived at the confluence of our five disparate themes, a genetic paradigm that has provided a powerful view of cancer. The seemingly countless causes of cancer-tobacco, sunlight, asbestos, chemicals, viruses, and many others-all these may work in a single way, by playing on a genetic keyboard, by damaging a few of the genes in our DNA. An enemy has been found, and we are beginning to understand its lines of attack.

In 1978, Susan Sontag published a widely read essay entitled "Illness as Metaphor." In that essay, Sontag described cancer in the following terms: ". . overlaid with mystification," "... a triumphant mutation," "... charged with the fantasy of inescapable fatality," "... a scandalous subject for poetry." Over the past decade, the force of science has taken some of the sting from those words. The mystification is in retreat, the triumphant mutation has been exposed, we see new ways by which to confront that inescapable fatality, there may even be reason for poetry.

\section{Acknowledgments}

This manuscript is an edited version of a Keynote Lecture delivered at the Keystone Symposium on Oncogenes in January of 1995. The lecture was prepared in part from secondary sources and informal personal recollections. I apologize for any errors or misinterpretations that knowledgeable readers may find. I thank the National Cancer Institute for long-standing support of my research. 


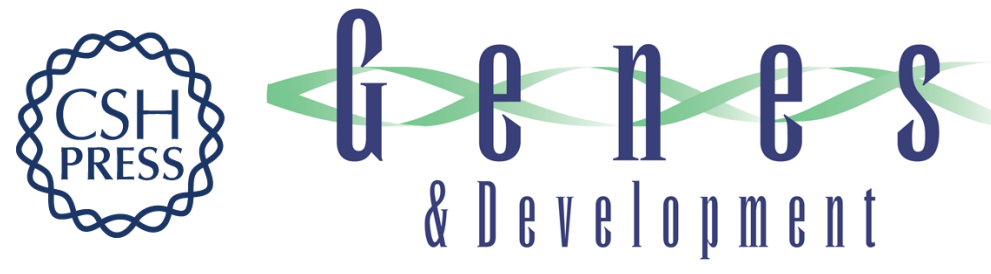

\section{Cancer: the rise of the genetic paradigm}

J. Michael Bishop

Genes Dev. 1995, 9:

Access the most recent version at doi:10.1101/gad.9.11.1309

\section{License}

Email Alerting

Receive free email alerts when new articles cite this article - sign up in the box at the top Service right corner of the article or click here.

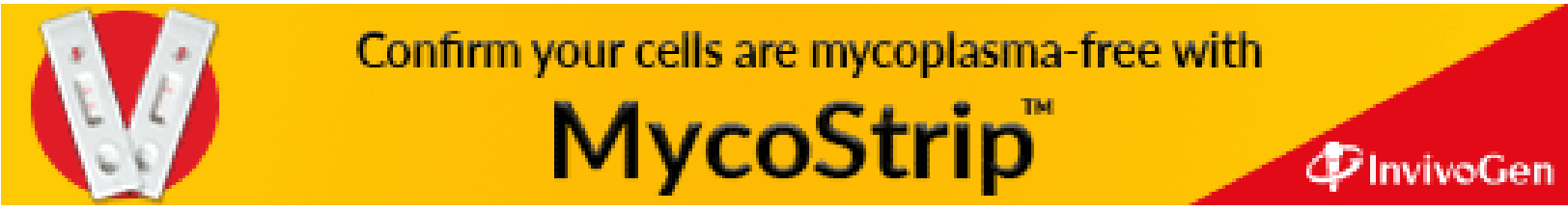

(C) 1995 by Cold Spring Harbor Laboratory Press 